\title{
Early-postnatal iron deficiency impacts plasticity in the dorsal and ventral hippocampus in piglets
}

Citation for published version (APA):

Nelissen, E., De Vry, J., Antonides, A., Paes, D., Schepers, M., van der Staay, F. J., Prickaerts, J., \& Vanmierlo, T. (2017). Early-postnatal iron deficiency impacts plasticity in the dorsal and ventral hippocampus in piglets. International Journal of Developmental Neuroscience, 59, 47-51. https://doi.org/10.1016/j.ijdevneu.2017.03.006

Document status and date:

Published: 01/06/2017

DOI:

10.1016/j.ijdevneu.2017.03.006

Document Version:

Publisher's PDF, also known as Version of record

Document license:

Taverne

Please check the document version of this publication:

- A submitted manuscript is the version of the article upon submission and before peer-review. There can be important differences between the submitted version and the official published version of record.

People interested in the research are advised to contact the author for the final version of the publication, or visit the DOI to the publisher's website.

- The final author version and the galley proof are versions of the publication after peer review.

- The final published version features the final layout of the paper including the volume, issue and page numbers.

Link to publication

\footnotetext{
General rights Owners
rights.

- You may freely distribute the URL identifying the publication in the public portal. please follow below link for the End User Agreement:

www.umlib.nl/taverne-license

Take down policy

If you believe that this document breaches copyright please contact us at:

repository@maastrichtuniversity.nl

providing details and we will investigate your claim.
}

Copyright and moral rights for the publications made accessible in the public portal are retained by the authors and/or other copyright owners and it is a condition of accessing publications that users recognise and abide by the legal requirements associated with these

- Users may download and print one copy of any publication from the public portal for the purpose of private study or research.

- You may not further distribute the material or use it for any profit-making activity or commercial gain

If the publication is distributed under the terms of Article $25 \mathrm{fa}$ of the Dutch Copyright Act, indicated by the "Taverne" license above, 


\title{
Early-postnatal iron deficiency impacts plasticity in the dorsal and ventral hippocampus in piglets
}

\author{
Ellis Nelissen ${ }^{\mathrm{a}, 1}$, Jochen De Vry ${ }^{\mathrm{a}, 1}$, Alexandra Antonides ${ }^{\mathrm{b}}$, Dean Paes ${ }^{\mathrm{a}}$, Melissa Schepers ${ }^{\mathrm{c}}$, \\ Franz Josef van der Staay ${ }^{\mathrm{b}}$, Jos Prickaerts ${ }^{\mathrm{a}}$, Tim Vanmierlo, ${ }^{\mathrm{c}, *}$ \\ ${ }^{a}$ Dept. of Psychiatry and Neuropsychology, School for Mental Health and Neuroscience, Maastricht University, Maastricht, The Netherlands \\ ${ }^{\mathrm{b}}$ Behavior \& Welfare Group (formerly Emotion \& Cognition Group), Department of Farm Animal Health, Faculty of Veterinary Medicine, Utrecht University, Utrecht, The \\ Netherlands \\ ${ }^{c}$ Dept. of Neuroimmunology and Biochemistry, BIOMED, Hasselt University, Hasselt, Belgium
}

\section{A R T I C L E I N F O}

\section{Keywords:}

Iron deficiency

Neuronal plasticity

Pig

BDNF

\begin{abstract}
A B S T R A C T
In this study, we investigated whether alterations in plasticity markers such as brain-derived neurotrophic factor (BDNF), p75 neurotrophin receptor $\left(\mathrm{p} 75^{\mathrm{NTR}}\right)$ and tyrosine receptor kinase $\mathrm{B}$ (TrkB) are underlying iron deficiency (ID)-induced cognitive impairments in iron depleted piglets. Newborn piglets were either fed an irondepleted diet (21 mg Fe/kg) or an iron-sufficient diet ( $88 \mathrm{mg} \mathrm{Fe} / \mathrm{kg}$ ) for four weeks. Subsequently, eight weeks after iron repletion (190-240 mg Fe/kg) we found a significant decrease in mature BDNF (14 kDa) and proBDNF $(18 \mathrm{kDa}$ and $24 \mathrm{kDa})$ protein levels in the ventral hippocampus, whereas we found increases in the dorsal hippocampus. The phosphorylation of cAMP response element binding protein (CREB) follows the mature BDNF protein level pattern. No effects were found on BDNF and CREB protein levels in the prefrontal cortex. The protein levels of the high affinity BDNF receptor, TrkB, was significantly decreased in both dorsal and ventral hippocampus of ID piglets, whereas it was increased in the prefrontal cortex. Together, our data suggest a disrupted hippocampal plasticity upon postnatal ID.
\end{abstract}

\section{Introduction}

Nutritional iron deficiency (ID) in neonates and toddlers negatively affects brain development leading to prolonged functional and structural deficits in the central nervous system (CNS) (Beard and Connor, 2003; Walter, 2003; Beard, 2003; Grantham-McGregor and Ani, 2001; Lozoff et al., 2000). Iron is not only an essential micronutrient required for oxygen transport, it is also a required cofactor for key enzymes in neurotransmitter production (Beard, 2003; Dunkley et al., 2004; Wang et al., 2002). From late prenatal to early postnatal life, the brain undergoes the so-called brain growth spurt. This critical time frame is featured by high demands of iron needed to orchestrate neuronal connectivity and myelination (Dobbing and Sands, 1979; Connor and Menzies, 1996). ID particularly leads to deficiencies in prefrontal cortex and hippocampal signaling (Rao et al., 2013). Interestingly, many of the ID-induced CNS deficits do not recover upon iron repletion and eventually lead to sustained impairments (Bourque et al., 2008; Ranade et al., 2013; Yehuda et al., 1986). In a longitudinal follow-up study, it was shown that children who suffered from severe ID during infancy maintained mental and motor impairment, even ten years after the onset of iron treatment (Lozoff et al., 2000).

Although ID is often studied in rodents, the brain development of piglets more closely resembles human brain development than for instance rats, in part due to the similar timing of the brain growth spurt (Dobbing and Sands, 1979; Conrad et al., 2012). Both piglets and infants are prone to develop CNS deficits due to restrained perinatal iron availability, underscoring the necessity of iron-containing nutrition (Whiteker, 1965; Lipinski et al., 2010). Furthermore, the neonatal porcine and human brain structures are similar; sharing a similar gyral pattern and distribution of gray and white matter (Lind et al., 2007; Pond et al., 2000). Recently, we showed in piglets that pre-weaning dietary ID impairs later spatial learning and memory even after restoring nutritional iron levels (Antonides et al., 2015). Moreover, we confirmed lower iron content in the CA1 and dentate gyrus regions of the hippocampus.

The hippocampus plays an essential role in spatial learning and memory: hippocampal-cortical interactions produce memory traces (Eichenbaum et al., 1996; Preston and Eichenbaum, 2013). Rodent

\footnotetext{
* Corresponding author at: Department of Immunology and Biochemistry. Biomedical Research Institute, Hasselt University. Martelarenlaan 42, B-3500 Hasselt, Belgium.

E-mail address: tim.vanmierlo@uhasselt.be (T. Vanmierlo).

1 These authors contributed equally to this paper.
} 
models for ID have already shown that iron is required for apical dendrite formation in the CA1 region of the hippocampus (Jorgenson et al., 2003; Brunette et al., 2010). Previously, it has been shown in rats that fetal-neonatal ID downregulated long-term hippocampal brainderived neurotrophic factor (BDNF) expression in adulthood despite complete iron repletion (Tran et al., 2009). Hippocampal BDNF signaling is strongly associated with synaptic plasticity and memory formation (Gomez-Palacio Schjetnan and Escobar-Rodriguez, 2007). In this study we investigate whether the previously found lower hippocampal iron content and impaired memory performance (Antonides et al., 2015), are linked to sustained impaired BDNF signaling in the hippocampus and prefrontal cortex in piglets. Protein levels of the plasticity markers BDNF, TrkB, p75 ${ }^{\mathrm{NTR}}$, CREB, synaptophysin, PSD95, and NeuN in the hippocampus and prefrontal cortex were measured.

\section{Materials and methods}

\section{Ethics note}

This study was reviewed and approved by the local animal ethics committee of Utrecht University (DEC, DierExperimenten Commissie) and was conducted in accordance with the recommendations of the EU directive 86/609/EEC. All efforts were made to minimize the number of animals used and to avoid suffering.

\subsection{Animals and housing}

The brain tissue used in this study is derived from the animals described in Antonides et al. (Antonides et al., 2015). In brief, hippocampal and prefrontal cortex samples were isolated from piglets [(Terra $x$ Finnish landrace) $x$ Duroc mix] bred at the Faculty of Veterinary Medicine of Utrecht University. Two male sibling piglets with a normal body weight were selected from each of ten different litters (Antonides et al., 2015). The piglets were separated from the sow after 4-6 days. One piglet of each pair was randomly assigned to the treatment group $(n=10)$ and the other piglet to the control group $(n=10)$. The piglets in the control group were given a $200 \mathrm{mg}$ iron dextran injection (Gleptosil, $200 \mathrm{mg}$ as gleptoferron MS Schippers, Lommel, Belgium) and fed a control milk diet ( $88 \mathrm{mg} \mathrm{Fe} / \mathrm{kg}$ ) for four weeks. The piglets of the treatment group were given a saline injection and were fed an iron deficient (ID) milk diet (21 mg Fe/kg). Starting after 4 weeks on the iron-deficient or control diet, all piglets received a balanced, iron-sufficient diet (190-240 mg Fe/kg) for eight weeks. They were tested in a complex spatial holeboard task to assess the effects of pre-weaning iron deficiency on cognitive performance between 3 and 8 weeks after dietary treatment (Antonides et al., 2015).

Two ID piglets were euthanized during the first week as they did not gain weight as expected. One control animal died unexpectedly at 11 weeks. At 12 weeks of age, all animals were euthanized by an intracardial injection with pentobarbital (Euthasol ${ }^{\circledR}$, AST Farma B.V. Oudewater, The Netherlands). Directly afterwards, brains were dissected and weighed. The prefrontal cortex and both hippocampi were then carefully removed and weighed, after which the right hippocampus was cut in half. Prefrontal cortex, and the ventral and dorsal hippocampus were then snap frozen in liquid nitrogen and stored at $-80^{\circ} \mathrm{C}$ until further use.

\subsection{Sample preparation}

Approximately $500 \mathrm{mg}$ of the brain samples were homogenized in $1 \mathrm{ml}$ lysis buffer (100 mM Tris- $\mathrm{HCl}, 200 \mathrm{mM} \mathrm{NaCl}, 1 \mathrm{mM}$ EDTA, $2 \mathrm{mM}$ DTT, $0.05 \%$ triton, 1 tablet complete protease inhibitor mix $/ 20 \mathrm{ml}$ buffer (Roche, Vilvoorde, Belgium), 1 tablet PhosSTOP phosphatase inhibitor cocktail/10 ml buffer (Roche) using a mini-Bead-Beater (BioSpec products, Bartlesville, OK, USA). Samples were homogenized three times for $30 \mathrm{~s}$ with $5 \mathrm{~min}$ cooling on ice between runs. After $30 \mathrm{~min}$ cooling on ice, samples were centrifuged at $16,000 \mathrm{~g}$ for $20 \mathrm{~min}$. $\left(4{ }^{\circ} \mathrm{C}\right.$ ), and the supernatant was divided into aliquots and stored at $-80{ }^{\circ} \mathrm{C}$ until further use. Protein concentrations were determined with the Bio-Rad $D C^{\mathrm{TM}}$ protein assay (Bio-Rad Laboratories, Inc.).

\subsection{Western blot}

Brain homogenates were separated with SDS-PAGE. Proteins were transferred onto a PVDF membrane, which was subsequently blocked (50\% Odyssey blocking buffer in PBS, Li-Cor, Lincoln, NE) for $1 \mathrm{~h}$ at room temperature. The membranes were incubated with primary antibody overnight at $4{ }^{\circ} \mathrm{C}$. Antibodies used were $1: 250$ rabbit antiTrkB (\#4606, Cell signaling technologies Beverly, MA), 1:250 rabbit anti-pTrkB (\#ABN1381, Millipore Billerica, MA), 1:1000 rabbit antip75 ${ }^{\mathrm{NTR}}$ (\#07-476, Millipore Billerica, MA), 1:1000 mouse anti-synaptophysin (\#MAB5258, Millipore), 1:100 rabbit anti-pCREB (\#9198S, Cell signaling technologies), 1:1000 mouse anti-CREB (\#9104, Cell signaling technologies), 1:500 mouse anti-NeuN (\#MAB377, Millipore), 1:2000 mouse anti-PSD95 (\#0711, QED Bioscience inc. San Diego, CA), and 1:600 rabbit anti-BDNF (\#20981, Santa Cruz Biotechnologies Santa Cruz, CA). For normalization, either GAPDH or $\beta$-actin was used: 1:2,000.000 mouse anti-GAPDH (\#10R-G109A, Fitzgerald Huissen, $\mathrm{NL}$ ), and 1:2000 mouse anti- $\beta$-actin (\#F0110, Santa Cruz Biotechnologies). The membranes were washed with PBS and PBSTween, and subsequently incubated with secondary antibody for $1 \mathrm{~h}$ at room temperature: 1:5000 goat anti-rabbit IRDye 800 (\#926-32211, LiCor), and 1:10,000 donkey anti-mouse IRDye 680 (\#926-32222, LiCor). Membranes were washed in PBS and PBS-Tween and fluorescent protein bands were visualized using the Odyssey Infrared Imaging System (Li-Cor). ImageJ (http://imagej.nih.gov/ij/) was used to quantify the fluorescent protein bands.

\subsection{Statistical analysis}

All data were analyzed using the statistical software program SAS (version 9.4, SAS Institute, Cary, NC). First, residuals of all variables were tested for normality using the Shapiro-Wilk test (SAS POC UNIVARIATE). The pCREB/CREB ratio was $\log 10$ transformed for statistical analysis, and visualized as non-transformed. The effects of iron deficiency at 12 weeks of age were analyzed using a mixed model ANOVA (SAS PROC MIXED) with the fixed effect treatment and with litter as random effect. One outlier in $18 \mathrm{kDa}$ proBDNF/mBDNF ratio for the dorsal hippocampus was detected using the online outlier detector QuickCalcs (GraphPad Software, Inc., La Jolla, CA) and removed.

\section{Results}

Whereas in the dorsal hippocampus of ID piglets mature BDNF (mBDNF) was increased $(\mathrm{p}<0.05)$, it was decreased in the ventral part of the hippocampus of ID piglets ( $\mathrm{p}<0.001$; Fig. 1A). No effects were found on mBDNF protein levels in the prefrontal cortex. In line with the mBDNF protein levels, the $18 \mathrm{kDa}$ and $24 \mathrm{kDa}$ proBDNF fragments were increased in the dorsal hippocampus of ID piglets $(\mathrm{p}<0.05)$, while both fragments were decreased in the ventral hippocampus ( $<0.05$ and $\mathrm{p}<0.01$; Fig. 1B, C).

The $18 \mathrm{kDa}$ and $24 \mathrm{kDa}$ proBDNF/mBDNF ratios in the dorsal hippocampus were not affected by ID. In contrast, the $24 \mathrm{kDa}$ proBDNF/mBDNF decreased in the ventral hippocampus in ID $(\mathrm{p}<0.05)$. ID did not affect the proBDNF/mBDNF ratio in the prefrontal cortex (Fig. 1D, E). Together, BDNF protein levels are shown to be disturbed in the hippocampus of ID piglets. Regarding the BDNF receptors, ID did not affect the p $75^{\mathrm{NTR}}$ protein levels in the dorsal hippocampus, ventral hippocampus, or prefrontal cortex (Fig. 1F). In contrast, protein levels of the high affinity BDNF receptor TrkB were reduced in ID piglets in both the dorsal $(\mathrm{p}<0.05)$ and ventral hippocampus $(\mathrm{p}<0.05)$, while increased TrkB protein levels were 
A

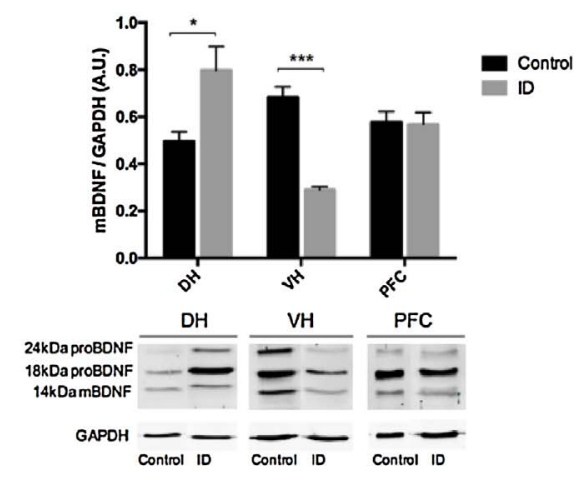

D

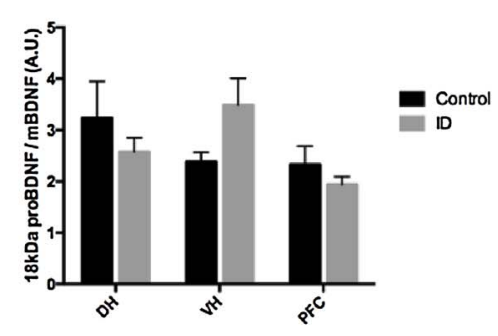

G

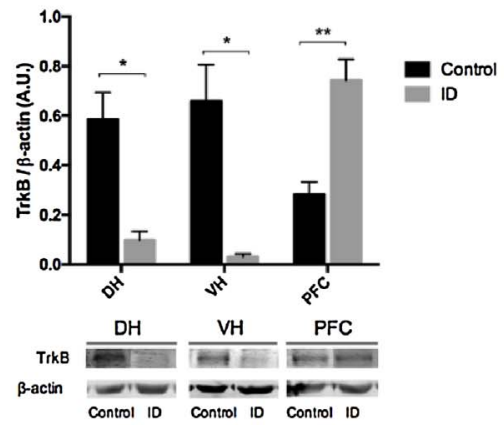

$\mathbf{J}$
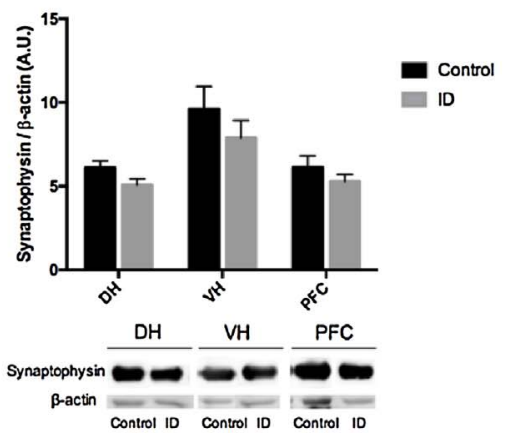

B

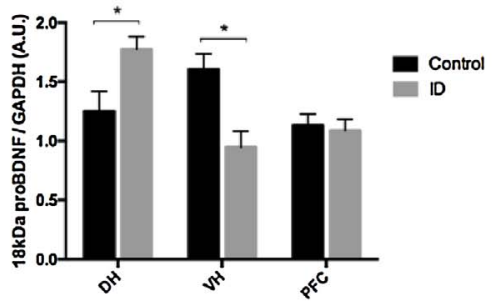

E

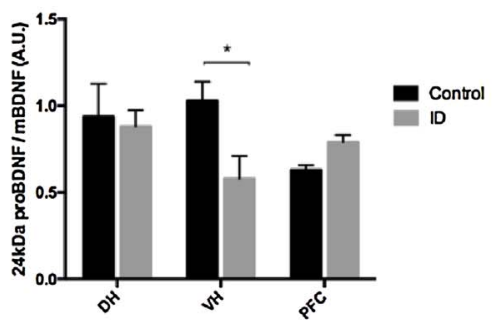

H
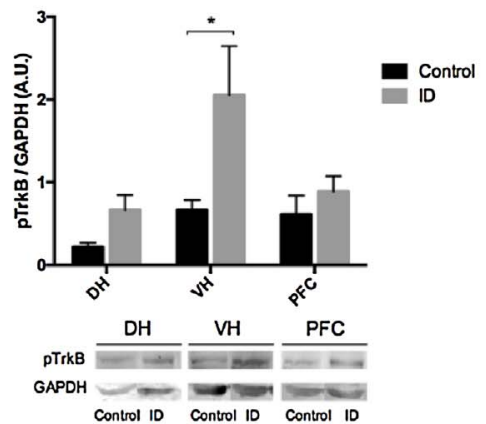

K

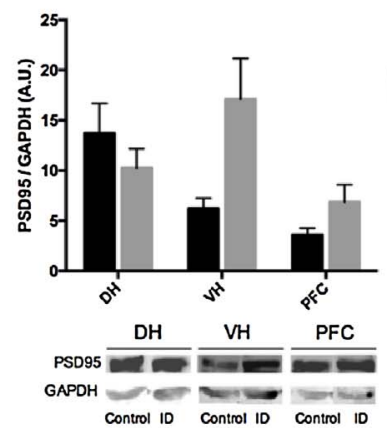

C

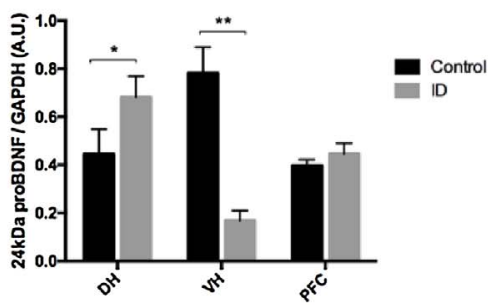

$\mathbf{F}$

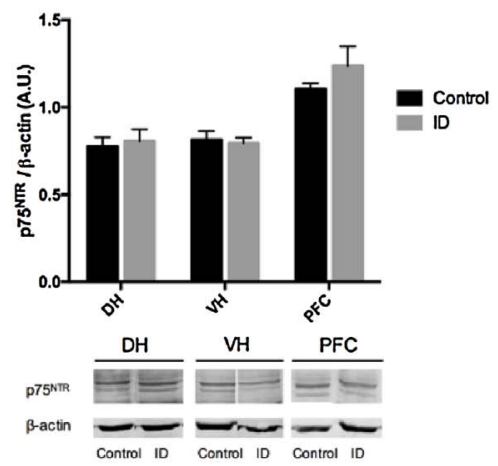

I
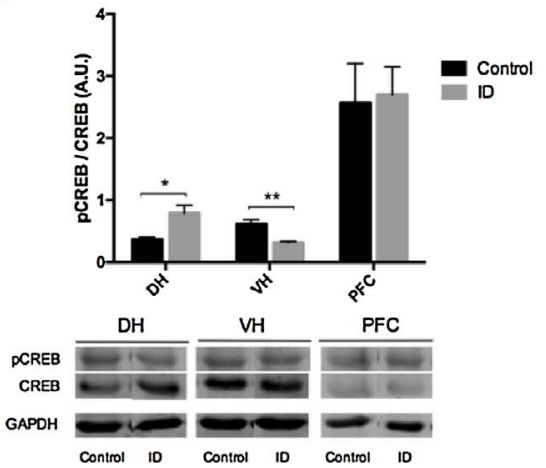

L

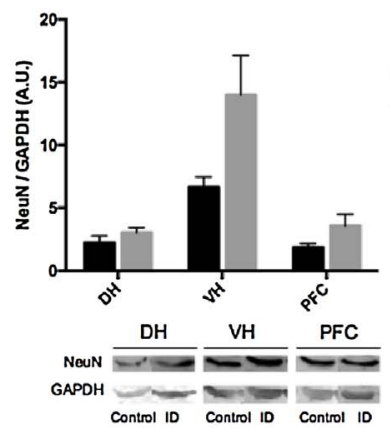

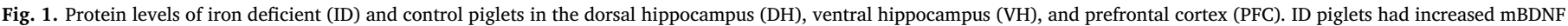

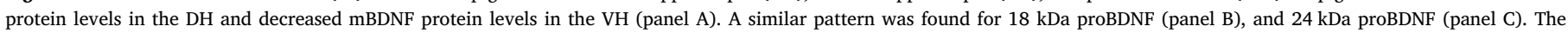

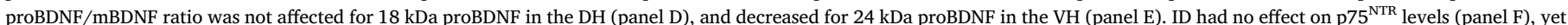

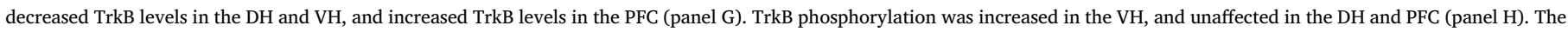

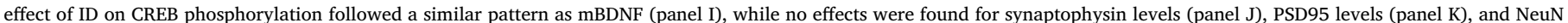
levels (panel L). ${ }^{*} \mathrm{P}<0.05$; ${ }^{* *} \mathrm{P}<0.01$; ${ }^{* * *} \mathrm{P}<0.001$; bars are represented as mean + SEM per group. 
found in the prefrontal cortex ( $\mathrm{p}<0.01$, Fig. 1G). TrkB phosphorylation was found to be increased in the ventral hippocampus $(\mathrm{P}<0.05)$, whereas the dorsal hippocampus and prefrontal cortex remained unaffected (Fig. 1H). In line with an increased level of mBDNF in the dorsal hippocampus of ID piglets, an increase in the ratio pCREB/CREB was detected in ID piglets ( $\mathrm{p}<0.05$ ). The decrease in MBDNF in the ventral hippocampus is reflected by a decrease of pCREB/CREB in the ventral hippocampus of ID piglets ( $\mathrm{p}<0.01$, Fig. 1I). Synaptophysin, PSD95, and NeuN protein levels were not affected in either of the CNS regions investigated (Fig. 1J-L).

\section{Discussion}

In the present study, we found that early postnatal anemic ID leads to reduced mBDNF levels, less TrkB yet more phosphorylated TrkB, and reduced phosphorylation of CREB in the ventral hippocampus. Interestingly, in the dorsal hippocampus, we found an increase in mature BDNF and phosphorylated CREB, despite lower TrkB protein levels following ID. Multiple studies have shown a direct correlation between early developmental ID and cognitive performance (Bourque et al., 2008; Ranade et al., 2013; Yehuda et al., 1986). In particular, it has recently been demonstrated that sustained anemic ID in pre-school aged children interfered with later social and emotional development (Chang et al., 2011). Recently, we and others confirmed that preweaning ID-induced anemia in neonatal piglets resulted in a sustained impaired learning performance and concomitant reduction in hippocampal white matter volume, with learning impaired even after iron repletion (Antonides et al., 2015; Leyshon et al., 2016). In fact, the findings from Antonides et al. (Antonides et al., 2015), namely sustained impaired learning performance in a cognitive holeboard task, were derived from the same piglets as used for this study, which means that the piglets used for this study were found to have cognitive deficits.

The ventral hippocampus is mainly involved in anxiety related behavior (Fanselow and Dong, 2010). Our observed decrease in mBDNF protein levels and the decrease in CREB phosphorylation in the ventral hippocampus of ID piglets suggests to underlie a reduced plasticity. The disturbed BDNF signaling in the ventral hippocampus upon ID in piglets is in line with the reported deficits in social and emotional behavior in ID children (Chang et al., 2011), since emotional behavior in primates involves the signaling in the anterior hippocampus, which is the primate's substrate for the piglet's and rodent's ventral hippocampus (Fanselow and Dong, 2010). The ventral hippocampus also showed a reduction in $18 \mathrm{kDa}$ proBDNF, and $24 \mathrm{kDa}$ proBDNF. One potential mechanism leading to reduced BDNF levels was recently proposed by Tran et al. and focuses on epigenetic chromatin remodeling at the Bdnf locus (Tran et al., 2015). It was reported that early-life iron deficiency induced stable histone modifications (H4 deacetylation, increased $\mathrm{H} 3$ K27me3 enrichment and decreased H3 K4me3 enrichment) at the BdnfIV promoter. This could possibly lead to chromatin remodeling and thereby reduce $B d n f$-IV transcription. In addition, the piglets were found to be anemic after iron depletion, with a highly significant reduction in serum iron content, hematocrit, and hemoglobin levels at the end of the ID diet compared to control animals (see Antonides et al. (Antonides et al., 2015) for details), which suggests a reduced systemic oxygen availability. This reduced oxygen availability may also lead to altered BDNF levels. Interestingly, TrkB phosphorylation was found to be increased in the ventral hippocampus, which would be indicative of increased plasticity. However, this may be a compensatory mechanism to the decreased mBDNF, TrkB, and CREB phosphorylation levels. Additionally, the $24 \mathrm{kDa}$ proBDNF/mBDNF ratio decreased upon ID, indicating a proportional increase of mBDNF, which could partly explain the observed increase in TrkB phosphorylation. Interestingly, we found a positive correlation $(\mathrm{r}=0.59$; $\mathrm{P}<0.05)$ between mBDNF levels in the ventral hippocampus and reference memory performance (as obtained from Antonides et al. (Antonides et al., 2015)), suggesting that indeed reduced mBDNF signaling in $\mathrm{VH}$ is indirectly related to the memory impairments.

Although the dorsal hippocampus is mainly involved in learning and memory processes (Fanselow and Dong, 2010), no change in $24 \mathrm{kDa}$ proBDNF/mBDNF ratio, and $18 \mathrm{kDa}$ proBDNF/mBDNF ratio was found, despite an absolute increase in both mBDNF and proBDNF fragments. ProBDNF, which exists in multiple sizes, has a high affinity for the p $75^{\mathrm{NTR}}$ receptor, whereas $\mathrm{mBDNF}$ has a high affinity for the TrkB receptor (Longo and Massa, 2013; Huang and Reichardt, 2003). Activation of $\mathrm{p} 75^{\mathrm{NTR}}$ is believed to elicit neurodegenerative effects, whereas activation of TrkB results in neuroprotective effects. This means that the observed increase in mBDNF could result in neuroprotection, while the increased proBDNF suggests increased neurodegeneration. This, together with the unchanged proBDNF/mBDNF ratios, suggests that there is a balanced upregulation of all BDNF fragments. These findings are rather unexpected since iron deficiency has been reported to reduce BDNF levels in the hippocampus, though no specific details on the different BDNF forms were given (Tran et al., 2009; Tran et al., 2008; Estrada et al., 2014). In addition, the protein levels of TrkB were significantly reduced in both dorsal and ventral hippocampus, yet the $p 75^{\mathrm{NTR}}$ receptor levels remained stable. This suggests a shift toward p75 ${ }^{\mathrm{NTR}}$ signaling over TrkB signaling in both hippocampal regions of ID piglets. Interestingly, TrkB phosphorylation remained unchanged in the dorsal hippocampus, while TrkB levels were reduced by ID. This suggests increased TrkB activity, which is in line with the increased mBDNF protein levels. Additionally, we found a negative correlation $(\mathrm{r}=-0.67 ; \mathrm{P}<0.01)$ between mBDNF levels in the dorsal hippocampus and reference memory performance (as obtained from Antonides et al. (Antonides et al., 2015)), which points at a potential compensatory mechanism for the reduced TrkB levels.

In line with the mBDNF data, CREB phosphorylation was found to be increased in the dorsal hippocampus. Binding of mBDNF to TrkB results in CREB phosphorylation, which subsequently results in expression of neuroprotective proteins, such as BDNF itself (Shieh et al., 1998; Finkbeiner, 2000). Increased CREB phosphorylation would therefore increase neuronal plasticity. However, during neuronal development, the brain highly depends on an orchestrated pattern of apoptosis and neurogenesis (Buss et al., 2006; Jacobson et al., 1997). Disruption of this pattern could deregulate neuronal development. Therefore, the observed increase in CREB phosphorylation may disrupt this pattern and in fact impair neuronal development, resulting in later cognitive and behavioral deficits. Moreover, increased CREB phosphorylation suggests increased TrkB activation, which can be explained by the increased mBDNF levels. However, despite this increased CREB phosphorylation, the balance between $\mathrm{p} 75^{\mathrm{NTR}}$ and TrkB signaling seems to be affected, which may suggest that the emphasis shifts toward neurodegeneration.

The prefrontal cortex, in contrast to the hippocampus, is hardly affected by ID regarding BDNF levels and CREB phosphorylation, except for an increase in TrkB protein levels. An increase in TrkB protein levels would have neuroprotective effects (Longo and Massa, 2013; Huang and Reichardt, 2003). However, as no effects were found for CREB phosphorylation, this increased TrkB protein levels does not seem to lead to increased TrkB signaling. Indeed, TrkB phosphorylation did not differ between ID and control piglets, whereas TrkB protein levels increased upon ID, suggesting a relative reduction in TrkB activation in the prefrontal cortex of ID piglets. Together, the data suggests that the prefrontal cortex is mostly spared in ID. This is supported by Rytych et al. (Rytych et al., 2012) who reported a decreased hippocampal-dependent learning upon 4 weeks of ID. Interestingly, in contrast to the hippocampus, PFC iron concentrations were not influenced by ID. These findings support the largely unaltered levels of the neuroplasticity markers in the PFC such BDNF, pCREB/CREB, synaptophysin, and PSD95. Together, it appears that the hippocampus is more vulnerable to early ID compared to the PFC.

Interestingly, the synaptophysin protein levels were not affected by ID in the hippocampus or prefrontal cortex. Synaptophysin is a synaptic 
vesicle protein that is considered to be a presynaptic marker, and it has a role in synaptic plasticity (Janz et al., 1999; Greengard et al., 1993). This may suggest that there is less effective post-synaptic signaling. In line herewith, protein levels of the post-synaptic marker PSD95 remained unchanged upon ID. This suggests that it is not necessarily plasticity at the level of the synapse that is affected by ID. Furthermore, NeuN protein levels were not affected by ID in the regions investigated. Since NeuN is a neuron differentiation marker (Gusel'nikova and Korzhevskiy, 2015), this suggests that neuron differentiation is not affected by ID. In the dorsal hippocampus, synaptophysin levels did not increase despite the observed mBDNF increase. Since we also found increased proBDNF in this region, and no difference in the proBDNF/ mBDNF ratio, it is likely that the dual increase in mBDNF and proBDNF out levels each other's effect on neuroplasticity. Taken together, this may put a big emphasis on the role of BDNF in the effects of ID.

Together, our data support the correlation between developmental anemic iron deficiency and the cognitive and morphological distortion found in previous studies (Antonides et al., 2015; Chang et al., 2011). An impaired hippocampal BDNF protein expression pattern was found in the ventral hippocampus, and reduced protein levels of its receptor TrkB were found in both dorsal and ventral hippocampus of ID piglets. Yet, the exact mechanism underlying the disrupted protein levels of players in the BDNF signaling cascade upon ID remains elusive and warrants further investigations. Together, our data suggest disrupted hippocampal plasticity upon early-postnatal ID.

\section{Acknowledgement}

This work was supported by Fonds voor Wetenschappelijk Onderzoek (FWO, 12G0817N).

\section{References}

Antonides, A., Schoonderwoerd, A.C., Scholz, G., Berg, B.M., 2015. Nordquist RE, van der Staay FJ: Pre-weaning dietary iron deficiency impairs spatial learning and memory in the cognitive holeboard task in piglets. Front Behav. Neurosci. 9, 291.

Beard, J.L., Connor, J.R., 2003. Iron status and neural functioning. Annu. Rev. Nutr. 23, $41-58$.

Beard, J., 2003. Iron deficiency alters brain development and functioning. J. Nutr. 133 (5 Suppl 1), 1468S-1472S.

Bourque, S.L., Iqbal, U., Reynolds, J.N., Adams, M.A., Nakatsu, K., 2008. Perinatal iron deficiency affects locomotor behavior and water maze performance in adult male and female rats. J. Nutr. 138 (5), 931-937.

Brunette, K.E., Tran, P.V., Wobken, J.D., Carlson, E.S., Georgieff, M.K., 2010. Gestational and neonatal iron deficiency alters apical dendrite structure of CA1 pyramidal neurons in adult rat hippocampus. Dev. Neurosci. 32 (3), 238-248.

Buss, R.R., Sun, W., Oppenheim, R.W., 2006. Adaptive roles of programmed cell death during nervous system development. Annu. Rev. Neurosci. 29, 1-35.

Chang, S., Wang, L., Wang, Y., Brouwer, I.D., Kok, F.J., Lozoff, B., et al., 2011. Irondeficiency anemia in infancy and social emotional development in preschool-aged Chinese children. Pediatrics 127 (4), e927-33.

Connor, J.R., Menzies, S.L., 1996. Relationship of iron to oligodendrocytes and myelination. Glia 17 (2), 83-93.

Conrad, M.S., Dilger, R.N., Johnson, R.W., 2012. Brain growth of the domestic pig (Sus scrofa) from 2 to 24 weeks of age: a longitudinal MRI study. Dev. Neurosci. 34 (4), 291-298.

Dobbing, J., Sands, J., 1979. Comparative aspects of the brain growth spurt. Early Hum. Dev. 3 (1), 79-83.

Dunkley, P.R., Bobrovskaya, L., Graham, M.E., von Nagy-Felsobuki, E.I., Dickson, P.W., 2004. Tyrosine hydroxylase phosphorylation: regulation and consequences. J. Neurochem. 91 (5), 1025-1043.

Eichenbaum, H., Schoenbaum, G., Young, B., Bunsey, M., 1996. Functional organization of the hippocampal memory system. Proc. Natl. Acad. Sci. U. S. A. 93 (24), $13500-13507$.

Estrada, J.A., Contreras, I., Pliego-Rivero, F.B., Otero, G.A., 2014. Molecular mechanisms of cognitive impairment in iron deficiency: alterations in brain-derived neurotrophic factor and insulin-like growth factor expression and function in the central nervous system. Nutr. Neurosci. 17 (5), 193-206.

Fanselow, M.S., Dong, H.W., 2010. Are the dorsal and ventral hippocampus functionally distinct structures? Neuron 65 (1), 7-19.

Finkbeiner, S., 2000. CREB couples neurotrophin signals to survival messages. Neuron 25 (1), 11-14.

Gomez-Palacio Schjetnan, A., Escobar-Rodriguez, M.L., 2007. [Memory coding and retention: brain-derived neurotrophic factor (BDNF) in synaptic plasticity]. Rev. Neurol. 45 (7), 409-417.

Grantham-McGregor, S., Ani, C., 2001. A review of studies on the effect of iron deficiency on cognitive development in children. J. Nutr. 131 (2S-2), 649S-666S (discussion 66S-68S).

Greengard, P., Valtorta, F., Czernik, A.J., Benfenati, F., 1993. Synaptic vesicle phosphoproteins and regulation of synaptic function. Science 259 (5096), 780-785.

Gusel'nikova, V.V., Korzhevskiy, D.E., 2015. NeuN as a neuronal nuclear antigen and neuron differentiation marker. Acta Nat. 7 (2), 42-47.

Huang, E.J., Reichardt, L.F., 2003. Trk receptors: roles in neuronal signal transduction. Annu. Rev. Biochem 72, 609-642.

Jacobson, M.D., Weil, M., Raff, M.C., 1997. Programmed cell death in animal development. Cell 88 (3), 347-354.

Janz, R., Sudhof, T.C., Hammer, R.E., Unni, V., Siegelbaum, S.A., Bolshakov, V.Y., 1999. Essential roles in synaptic plasticity for synaptogyrin I and synaptophysin I. Neuron 24 (3), 687-700.

Jorgenson, L.A., Wobken, J.D., Georgieff, M.K., 2003. Perinatal iron deficiency alters apical dendritic growth in hippocampal CA1 pyramidal neurons. Dev. Neurosci. 25 (6), 412-420.

Leyshon, B.J., Radlowski, E.C., Mudd, A.T., Steelman, A.J., Johnson, R.W., 2016. Postnatal iron deficiency alters brain development in piglets. J. Nutr. 146 (7), 1420-1427.

Lind, N.M., Moustgaard, A., Jelsing, J., Vajta, G., Cumming, P., Hansen, A.K., 2007. The use of pigs in neuroscience: modeling brain disorders. Neurosci. Biobehav. Rev. 31 (5), 728-751.

Lipinski, P., Starzynski, R.R., Canonne-Hergaux, F., Tudek, B., Olinski, R., Kowalczyk, P., et al., 2010. Benefits and risks of iron supplementation in anemic neonatal pigs. Am. J. Pathol. 177 (3), 1233-1243.

Longo, F.M., Massa, S.M., 2013. Small-molecule modulation of neurotrophin receptors: a strategy for the treatment of neurological disease. Nat. Rev. Drug Discov. 12 (7), 507-525.

Lozoff, B., Jimenez, E., Hagen, J., Mollen, E., Wolf, A.W., 2000. Poorer behavioral and developmental outcome more than 10 years after treatment for iron deficiency in infancy. Pediatrics 105 (4), E51.

Pond, W.G., Boleman, S.L., Fiorotto, M.L., Ho, H., Knabe, D.A., Mersmann, H.J., et al., 2000. Perinatal ontogeny of brain growth in the domestic pig. Proc. Soc. Exp. Biol. Med. Soc. Exp. Biol. Med. 223 (1), 102-108.

Preston, A.R., Eichenbaum, H., 2013. Interplay of hippocampus and prefrontal cortex in memory. Curr. Biol.: CB 23 (17), R764-73.

Ranade, S.C., Nawaz, S., Chakrabarti, A., Gressens, P., Mani, S., 2013. Spatial memory deficits in maternal iron deficiency paradigms are associated with altered glucocorticoid levels. Horm. Behav. 64 (1), 26-36.

Rao, R., Tkac, I., Unger, E.L., Ennis, K., Hurst, A., Schallert, T., et al., 2013. Iron supplementation dose for perinatal iron deficiency differentially alters the neurochemistry of the frontal cortex and hippocampus in adult rats. Pediatr. Res. 73 (1), 31-37.

Rytych, J.L., Elmore, M.R., Burton, M.D., Conrad, M.S., Donovan, S.M., Dilger, R.N., et al., 2012. Early life iron deficiency impairs spatial cognition in neonatal piglets. J. Nutr. 142 (11), 2050-2056.

Shieh, P.B., Hu, S.C., Bobb, K., Timmusk, T., Ghosh, A., 1998. Identification of a signaling pathway involved in calcium regulation of BDNF expression. Neuron 20 (4), 727-740.

Tran, P.V., Carlson, E.S., Fretham, S.J., Georgieff, M.K., 2008. Early-life iron deficiency anemia alters neurotrophic factor expression and hippocampal neuron differentiation in male rats. J. Nutr. 138 (12), 2495-2501.

Tran, P.V., Fretham, S.J., Carlson, E.S., Georgieff, M.K., 2009. Long-term reduction of hippocampal brain-derived neurotrophic factor activity after fetal-neonatal iron deficiency in adult rats. Pediatr. Res. 65 (5), 493-498.

Tran, P.V., Kennedy, B.C., Lien, Y.C., Simmons, R.A., Georgieff, M.K., 2015. Fetal iron deficiency induces chromatin remodeling at the Bdnf locus in adult rat hippocampus. Am. J. Physiol. Regul. Integr. Comp. Physiol. 308 (4), R276-82.

Walter, T., 2003. Effect of iron-deficiency anemia on cognitive skills and neuromaturation in infancy and childhood. Food Nutr. Bull. 24 (Suppl. 4), S104-S110.

Wang, L., Erlandsen, H., Haavik, J., Knappskog, P.M., Stevens, R.C., 2002. Threedimensional structure of human tryptophan hydroxylase and its implications for the biosynthesis of the neurotransmitters serotonin and melatonin. Biochemistry 41 (42), 12569-12574.

Whiteker, M.D., 1965. A postgraduate nutrition course for the practicing veterinarian 4a$\mathrm{n}$ utrient requirements of swine. Vet. Med. Small Anim. Clin.: VM, SAC 60, 856-859.

Yehuda, S., Youdim, M.E., Mostofsky, D.I., 1986. Brain iron-deficiency causes reduced learning capacity in rats. Pharmacol. Biochem. Behav. 25 (1), 141-144. 